\title{
MIGUEL ASÍN PALACIOS Y LA FILOSOFÍA MUSULMANA*
}

\author{
Rafael Ramón Guerrero \\ Universidad Complutense. Madrid
}

\section{RESUMEN}

Con motivo del cincuenta aniversario de la muerte de Miguel Asín Palacios, se pasa revista a su aportación a la historia de la filosofía en el Islam, en especial a la andalusí, a través de un breve análisis de sus principales escritos.

\begin{abstract}
On the ocasion if the fiftieth anniversary of the death of the distinguished aragonese arabist Miguel Asín Palacios, the autor reviews in this article the contribution of Asín to the history of Islamic philosophy, especially to the philosophy of Al-Andalus, through a brief analysis of his main writings.
\end{abstract}

Difícil resulta hablar de la polifacética vida de Miguel Asín Palacios, tanto por su rica personalidad, como por el conjunto de su variada obra. Y, aunque disponemos de un amplio estudio a él consagrado, el del Dr. José Valdivia Válor,' sin embargo su objeto central, como reza el subtítulo, es la mística musulmana tal como la viera Asín, por lo que sólo nos ofrece un aspecto limitado y parcial de su inmensa labor en pro del conocimiento del Islam.

Por ello, quiero aquí poner de relieve la aportación de Asín a un quehacer olvidado desde hacía mucho tiempo en España y en el que llegó a ser maestro inigualable: la recuperación de la filosofía que los musulmanes habían elaborado, especialmente la producida por los andalusíes. Una tarea en la que influyó, sin duda, uno de sus dos grandes modelos de vida.

* Este artículo es un extracto de la conferencia que con el título Asín Palacios y su aportación a la historia de la filosofía musulmana impartí el día 21 de noviembre de 1994, dentro del ciclo «En el cincuentenario de la muerte de Miguel Asín Palacios», organizado en Zaragoza por la Obra Cultural de Ibercaja.

1 D. Miguel Asin Palacios. Mística cristiana y mística musulmana. Madrid, Hiperión, 1992. 
Nos cuenta D. Juan Zaragüeta en la Necrología de D. Miguel Asín que «en lo humano tenía como dos modelos en que se inspiraba, y que eran el Cardenal Newman y el Cardenal Mercier, cuyos retratos ornaban su cuarto de trabajo». La admiración que Asín tuvo por Mercier, la refleja en las palabras que escribió en el homenaje internacional dedicado a éste: «El criterio en que he procurado inspirar mis estudios islámicos, cífrase en estas palabras del Cardenal Mercier: "Un medio para evitar el reproche de servilismo religioso que se hace a los eruditos cristianos es cultivar la ciencia por sí misma, sin buscar en ella directamente ningún interés de apologética"».3

Al confesar esta deuda, Asín Palacios estaba reconociendo también una de sus fuentes de inspiración en una de sus preocupaciones fundamentales, la filosofía árabe. Porque, en efecto, en el año 1887, Mercier, profesor de la Universidad de Lovaina, quiso fundar un Instituto Superior de Filosofía, para formación en el conocimiento de Tomás de Aquino, de los grandes escolásticos medievales y en el de las fuentes de éstos, entre las que se encontraba la filosofía árabe. Mercier era, además, consciente de que, para conocer dignamente esta filosofía, era necesario leer en su lengua original los textos árabes y tener una profunda base en los estudios islámicos.

Asín Palacios comprendió el espíritu que animaba la empresa del cardenal Mercier y se entregó de lleno a su realización. De la mano de sus maestros Codera y Ribera, se inició en el estudio de la lengua árabe y de la cultura y civilización islámicas. Fruto de esta dedicación fue su tesis doctoral sobre Algazel, presentada en 1896, y sus primeros trabajos sobre Ibn 'Arabî de Murcia y sobre Avempace de Zaragoza. Acerca de este último versa su primer estudio de estricta filosofía islámica, titulado «El filósofo zaragozano Avempace». Pero de los estudios de Asín sobre Avempace se ha ocupado el profesor Lomba.

Animado por D. Marcelino Menéndez Pelayo, que había juzgado su Tesis como miembro del tribunal, Asín se decidió a dar a la luz pública los frutos de sus investigaciones sobre Algazel (1057-1111), en un voluminoso escrito titulado Algazel. Dogmática, moral, ascética, ${ }^{5}$ primera de una serie de obras que luego consagraría al pensador persa. Aunque no es una obra en la que se ocupe estrictamente de la filosofía, pues en ella aborda las ideas teológicas y místicas de Algazel, sí vemos a un Asín Palacios muy familiarizado ya con la filosofía musulmana anterior a Algazel; con el desarrollo de la teología en el Islam; con la presencia de la filosofía griega en el mundo árabe; con la utilización por los teólogos as aríes del atomismo griego, para rechazar la concepción aristotélica de la eternidad del mundo; y, en fin, con el progreso de las ideas místicas en el Islam.

Algazel se había formado en el estudio de los filósofos orientales al-Fârâbî y Avicena. Expuso el pensamiento de éstos en su obra Las intenciones de los filósofos de manera tan

2 Anales de la Real Academia de Ciencias Morales y Políticas, cuaderno 2. ${ }^{\circ}, 1952$, p. 14.

3 Le Cardinal Mercier (1851-1926), Bruselas, 1927, p. 314.

4 Revista de Aragón. 1 (1900), pp. 193-197, 234-238, 278-281, 300-302; y 2 (1901), pp. 241-246, 301 303, 348-350.

5 Zaragoza, Comas Hnos, 1901. 
digna y excelente que, luego de traducida al latín, fue tomada por los escolásticos latinos por un manual de filosofía árabe. Impugnó después esta filosofía en el Tahâfut al-falâsifa ( «La destrucción de los filósofos») y se inclinó al ascetismo y al sufismo: Surgió así el autor del tratado Vivificación de las ciencias religiosas. En su estudio, Asín Palacios pone de relieve cómo Algazel se aprovechó tanto de la especulación teológica como metafísica y filosófica de sus predecesores en el Islam y cómo esta especulación está presente en todas sus obras, en especial en la Vivificación, cuyos principales pasajes traduce de forma clara y con singular encanto. Expone los conceptos algazelianos sobre la idea de Dios como fundamento del orden moral, sus esfuerzos por resolver la antinomia entre el libre albedrío y la presciencia divina y las doctrinas más importantes de Algazel, que luego ampliaría y desarrollaría en su gran obra en cuatro volúmenes La espiritualidad de Algazel y su sentido cristiano. ${ }^{6}$

En ese mismo año de 1901 publica un pequeño artículo dedicado a Abentufayl de Guadix, titulado «El filósofo autodidacto», ${ }^{7}$ donde divulga las ideas principales del escrito novelado del filósofo accitano, que había sido traducido el año anterior por el malogrado arabista D. Francisco Pons y Boigues. El filósofo autodidacto, según el decir de Menéndez Pelayo en el prólogo a esta traducción, es la obra filosófica más original y profunda de la literatura arábigo-hispana. Muy conocida en Europa desde su edición árabe y traducción latina, realizadas en Oxford en 1671, pronto circularon versiones en las principales lenguas europeas, que dan idea de la curiosidad que despertó entre los ilustrados.

A partir de aquí, casi todos los años Asín publicaría artículos o trabajos en los que revela sus conocimientos de filosofía en general o de filosofía árabe en particular, consciente del olvido en que esta faceta de los estudios islámicos había permanecido durante siglos. Afirmando que ya nadie, que de discreto se precie, se atreverá a negar lo que el siglo XIII debe a los filósofos árabes, Asín Palacios sostiene que, puesto que de lo que se trata es de conocer las ideas de escritores que emplearon una lengua distinta de la nuestra, es necesario traducir los textos filosóficos originales árabes. Y para llevar a cabo esta empresa, es preciso disponer de una cimentada instrucción en la gramática y en el léxico, a la que hay que añadir un conocimiento de los tecnicismos particulares que usaron los filósofos árabes, términos que no aparecen recogidos en los diccionarios usuales. Reconoce los apuros que en el tecnicismo filosófico experimentaron también los mismos árabes, cuando hubieron de traducir los textos griegos y, convencido de las ventajas que proporcionaría un diccionario que recogiera los principales términos técnicos de esta ciencia, compuso su «Bosquejo de un diccionario técnico de filosofía y teología musulmanas», ${ }^{8}$ donde adelanta las líneas generales de su proyecto.

En este «Bosquejo» define lo que para él constituye el ámbito de aplicación de la filosofía entre los árabes: las mismas ramas del saber que integraron la enciclopedia de los

6 Madrid, Ed. Imprenta Maestre, 1934-1941.

7 Revista de Aragón. 2 (1901), pp. 25-27, 57-60, 89-91.

8 Revista de Aragón. 5 (1903), pp. 179-189, 264-275, 343-359. 
peripatéticos y neoplatónicos, a saber, la lógica, la metafísica, las matemáticas, la física, la ética, la económica y la política; a ellas los árabes añadieron la medicina, las ciencias naturales, la alquimia, la astronomía, la mecánica y otras ciencias. Pero, dice Asín Palacios, hay que eliminar todas aquellas que desde el Renacimiento se han ido constituyendo en ciencias independientes de la filosofía. Por ello, un diccionario técnico de voces filosóficas deberá incluir sólo las palabras que expresen ideas que sean objeto actualmente de la filosofía: lógica, ontología, psicología, cosmología, teodicea y ética. Además, también debe contener las voces propias de las ciencias tradicionales o reveladas.

Publica a continuación uno de sus trabajos más celebrados, el editado en el homenaje a su maestro D. Francisco Codera, cuya cátedra de árabe de la Universidad de Madrid había ocupado Asín a la jubilación voluntaria de aquél. El trabajo lleva por título «El averroísmo teológico de Santo Tomás de Aquino». ${ }^{9}$ Aquí hace una nueva demostración de sus profundos conocimientos filosóficos. Señala cómo desde el primer momento el aristotelismo estuvo envuelto en la exégesis de los pensadores árabes, generalmente inspirados en el neoplatonismo, y estudia el problema de la razón y la fe en Siger de Brabante, santo Tomás y Averroes. Sostiene después que la doctrina de éste acerca de la fe y razón es radicalmente contraria a la que defendieron los averroístas; por ello, lejos de ser Averroes el maestro y patrocinador del racionalismo averroísta, fue su más radical adversario. Su doctrina coincide en todo con la del Doctor Angélico, no por casualidad, ni por el uso común de fuentes griegas, sino por la lectura que santo Tomás hizo de Maimónides, o, lo más probable, a través de los escritos del dominico español Raimundo Martín o Ramón Martí, experto en hebreo y en árabe, especialmente a través de su Pugio fidei adversus mauros et judaeos, en la que muestra conocer textos religiosos y filosóficos musulmanes y donde cita el Corán, a al-Fârâbî, Avicena, Algazel y, sobre todo, a Averroes y sus Comentarios a Tópicos y a Metafísica, sus Compendios, su Tahâfut y la Damîma (Epistola ad amicum).

Tomás de Aquino, según Asín, copió del Pugio fidei, en particular en su Summa contra gentes. «Para mí - afirma- no me cabe duda». «Raimundo Martín, de más edad, —sigue diciendo Asín- llevaba ya largos años de estudio y de trabajo sobre las fuentes árabes, cuando parece que Santo Tomás comenzó a componer su libro. Por otra parte, muchísimos capítulos de la Summa son idénticos literalmente a los del Pugio, y como las ideas comunes a ambos libros son a veces traducción literal de textos árabes de Algazel, Avicena, Averroes, etc., no es atrevido afirmar que Santo Tomás las tomaría de Raimundo Martín, especialista en el conocimiento de la filosofía musulmana. Sería inaudito suponer lo contrario».

Pues parece que fue inaudito, especialmente para muchos tomistas, que no podían aceptar tan fácilmente que santo Tomás pudiera plagiar textos de su correligionario Raimundo Martín. Así, dos años más tarde, en 1906, el P. Getino publicaba en Vergara un volumen de 109 páginas, con el mismo título que el artículo de Asín, en el que pretendía

9 Homenaje a D. Francisco Codera en su jubilación del profesorado, Zaragoza, Mariano Escar, 1904, pp. 271-331. 
rebatir toda la investigación del arabista. Aunque reconocía su desconocimiento de la lengua árabe y no tener a mano el Pugio fide i para compararlo con la Summa de santo Tomás, no vaciló en negar rotundamente la tesis de Asín y en afirmar que el Aquinate no pudo utilizar el texto de Martín. Es ésta una cuestión sobre la que aún andan discutiendo entre sí los especialistas en santo Tomás, sobre si leyó o no el Pugio fidei y si lo plagió o no en la Summa contra gentes, o si fue Ramón Martí el que se sirvió de Tomás de Aquino. ${ }^{10}$

Una nueva contribución al conocimiento de Algazel y de Averroes es el artículo titulado «Sens du mot Tehafot dans les oeuvres d'El Ghazali et d'Averroes», " en el que trata de precisar, frente a las distintas traducciones propuestas por algunos estudiosos, el sentido que esta palabra, Tahâfut, tenía para sus autores. Basándose en estudios filológicos y dejando explícitamente al margen la gramática, Asín llega a la conclusión, por el uso que de ese término hace su autor en diversos textos y en diferentes pasajes, de que Tahâfut alfalâsifa significa, para Algazel, «La precipitación irreflexiva de los peripatéticos».

La actitud adoptada por Averroes, al emprender en su Tahâfut al-tahâfut la refutación y crítica de Algazel, viene a confirmar plenamente la hipótesis de traducción propuesta, porque Asín encuentra bastantes textos del cordobés donde éste repite cuál ha sido el objeto que se ha propuesto al componer la obra. Para Averroes, tahâfut significa «solución prematura y precipitada de los problemas filosófico-teológicos». Al final del artículo, Asín Palacios reconoce la deuda que, para la elucidación de este término, ha contraído con el dominico Raimundo Martín, quien en su Pugio, al citar la obra de Algazel, la titula siempre Ruina seu Praecipitium philosophorum. Es un trabajo de Asín que tiene como raíces las mismas que su anterior estudio.

En el año 1908 presentaba una comunicación al Congreso Internacional de Orientalistas, celebrado en Copenhague, donde abordaba el estudio de otro filósofo andalusí, Ibn Tumlûs de Alcira, y donde daba a conocer su obra de lógica contenida en el manuscrito n. ${ }^{\circ} 649$ de la Biblioteca de El Escorial. En esta obra, el autor andalusí ofrece un resumen de la lógica, en un escrito con un cierto orden sistemático y donde muestra una perfecta asimilación de la materia y un propósito deliberado de no desempeñar el papel de mero comentarista, según dice Asín. Éste puso de manifiesto cómo se trata de un texto muy importante para la historia de la filosofía islámica en España, por las alusiones al estado de los estudios en su época y por señalar las alteraciones que experimentó el estrecho criterio teológico de los alfaquíes españoles, refractarios a toda novedad científica, pero dispuestos a aceptarla como ortodoxia una vez que se habían habituado a considerarla como algo tradicional. Indicó también

$10 C f$. el más reciente estado de la cuestión en E. Colomer: «La controversia islamo-judeo-cristiana en la obra apologética de Ramón Martí», en Diálogo filosófico-religioso entre cristianismo, judaísmo e islamismo durante la Edad Media en la Península Ibérica. Actes du Colloque international de San Lorenzo de El Escorial, 23-26 juin 1991, organisé par la Société Internationale pour l'Étude de la Philosophie Médiévale, édités par Horacio Santiago-Otero, Turnhout (Bélgica), Éditions Brepols, 1994, pp. 229-257, especialmente en pp. 240-242.

11 Revue Africaine, 1906, pp. 185-203. 
cómo Ibn Tumlûs, discípulo de Averroes, evitó escrupulosamente citar a su maestro por el estigma de incredulidad que sobre él ya pesaba, y cómo se sirvió de los escritos de al-Fârâbî en lugar de los comentarios de Avempace o del propio Averroes; se confiesa, en cambio, discípulo de Algazel, a cuyos libros de lógica atribuye su iniciación en la materia.

El texto de esta obra, con traducción castellana, lo publicaría Asín Palacios más tarde, con el título Introducción al arte de la lógica, por Abentomlús de Alcira. ${ }^{12}$ En el prólogo traza una somera biografía del autor, una descripción del manuscrito y una escueta valoración de la lógica de Ibn Tumlûs. Contribuía Asín Palacios, de esta manera y una vez más, a dar a conocer la importancia de la filosofía andalusí en sus mismos textos.

En marzo de 1914, D. Miguel Asín Palacios ingresaba como académico de número en la Real Academia de Ciencias Morales y Políticas, para ocupar la vacante dejada por Menéndez Pelayo. Su discurso de ingreso versó sobre Abenmasarra y su escuela. Estudio sobre los orígenes de la filosofía hispano-musulmana. ${ }^{13}$ En las palabras iniciales descubrimos la modestia con que Asín Palacios abordaba todos sus trabajos: «Lo único para lo que medianamente sirvo - dice- es para escudriñar con alguna paciencia, en los archivos de nuestro pasado, la historia de los sistemas filosóficos y teológicos de los pensadores hispano-musulmanes». ¡Menuda paciencia requirió el documentadísimo y amplísimo trabajo que en este discurso nos ofrece! En él hallamos nada menos que una profunda investigación sobre los orígenes de la filosofía en el Islam andalusí. Algo a lo que nadie antes se había atrevido.

Su objetivo, según confiesa al comienzo, es ofrecer «un modesto estudio de los orígenes del pensamiento filosófico-teológico en la España musulmana, en el cual se ponga de relieve, en medio de sus varias direcciones primitivas, una, la de los masarríes, verdadero sistema herético dentro del islam, con caracteres neoplatónicos, místicos y panteístas, que tienen su raigambre más honda en el alma española, y que a través de dos pensadores posteriores, Avicebrón, judío, y Abenarabi, musulmán, llegé a preocupar a la escolástica cristiana provocando en sus principales representantes seculares polémicas y deja oír todavía hoy sus últimos ecos en las especulaciones teosóficas de los sufies o místicos heterodoxos del islam, desde el África hasta la India».

Orígenes de la filosofía hispano-musulmana que desde el siglo X, en que se inicia, llegan, por una parte, a los medievales cristianos y, por otra, a los propios musulmanes de hoy. He aquí la importancia de la tarea a la que se entregó Asín en este discurso. Pero este trabajo no comienza en el siglo X y en la Córdoba de Ibn Masarra, sino que se inicia mucho antes, con Mahoma y su predicación, con los tres primeros siglos de vida islámica y con el desarrollo del pensamiento musulmán. Asín Palacios pasa revista a éste, desde sus primeras

12 Madrid, Imprenta Ibérica, 1916.

13 Discurso leído en el acto de su recepción en la Real Academia de Ciencias Morales y Políticas por D. Miguel Asin Palacios y contestación por el Excmo. Señor don Eduardo Sanz y Escartín el día 29 de marzo de 1914, Madrid, Imprenta Ibérica, 1914. 
formas y manifestaciones. Analiza diversas sectas, cuyas doctrinas, mezcladas con algunos elementos de la filosofía griega, contribuyeron a la difusión de éste dentro del Islam. Analiza también, brevemente, la corriente filosófica y la aparición del misticismo o movimiento sufí. Todo ello le permite situar en su contexto el surgimiento del pensamiento andalusí: «La historia del pensamiento filosófico-teológico en la España musulmana es un trasunto fiel de la cultura islámica oriental, sin nexo alguno, positivo y demostrado, con las tradiciones indígenas». Aquí está expresada la tesis central de Asín: el pensamiento andalusí nada debe a la anterior cultura romano-visigoda, sino que es fruto de lo que antes se había hecho en el Oriente musulmán. Y, aunque después se haya comprobado la existencia de algunos elementos de esta cultura en la de al-Andalus y aunque aún falten estudios sobre la contribución de los mozárabes a la civilización hispano-musulmana, la tesis conserva intacta su validez en sus líneas más generales.

Tras poner de relieve cómo la filosofía se introdujo en al-Andalus «no a cara descubierta, sino en compañía de las ciencias aplicadas u oculta bajo el disfraz de las herejías motáziles y batiníes», Asín comienza su estudio del personaje al que dedica el grueso de su discurso, Ibn Masarra de Córdoba, nacido en el año 883 y muerto un 20 de octubre del 931. La doctrina que sobre él expone ha sido magistralmente resumida por D. Emilio García Gómez: «Allí se estudia de mano maestra, sobre el oscuro fondo intelectual de los primeros siglos del islam español, la singular innovación de Ibn Masarra: su fusión del sistema plotiniano del Pseudo-Empédocles y de su teorema más característico (la jerarquía de las cinco sustancias presididas por una Materia Prima Intelectual) con elementos mu'ctazilíes,

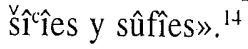

La extremada penuria de elementos con que Asín hubo de luchar para la reconstrucción del sistema masarrî se debe a una conjunción de circunstancias que de ordinario no suelen darse: el misterioso velo tras el que Ibn Masarra ocultaba su doctrina; el sello esotérico de sus escritos; el reducido número de sus discípulos; la tacha de herejía e impiedad con que se vieron señalados; y, en fin, la desaparición total de sus libros. Sólo por caminos indirectos pudo Asín Palacios rastrear e inducir algo de lo que habían sido las ideas del audaz pensador cordobés. Y su tesis fue calificada por Samuel Stern de «una ilusión», en la comunicación que éste presentó al IV Congreso de Estudios Árabes e Islámicos, celebrado en Coimbra y Lisboa en 1968. Sin embargo, como han mostrado posteriormente Cruz Hernández y Emilio Tornero, la tesis de Abenmasarra como seguidor del Pseudo-Empédocles, lejos de ser una ilusión, es irrefutable mientras no aparezcan testimonios en contrario.

La conclusión de Asín era la siguiente: «En el espléndido califato de Bagdad resucitan, desde el siglo VIII de nuestra era, varios sistemas neoplatónicos impregnados de un intenso misticismo cristiano, que se divulgan rápidamente merced a una copiosa literatura pseudónima y apócrifa. Uno de esos sistemas, el del Pseudo-Empédocles... es introducido en España durante el siglo XI por un musulmán de estirpe española, Abenmasarra el cordobés, que

14 «Esquema de una biografía», Al-Andalus, 9 (1944), pp. 277-278. 
consagra su vida a propagarlo entre sus correligionarios, amalgamado con las doctrinas y prácticas del sufismo, cristianas por su origen. La escuela mística y neoplatónica por él fundada, perpetúase en Andalucía hasta el siglo XI, e ingertada [sic] luego en el sufismo español de la escuela almeriense, pasa a fecundar la síntesis panteísta y teosófica del murciano Abenarabi y de su escuela, cuyas obras, divulgadas hasta nuestros días por los más remotos confines del Oriente y del Occidente islámico, llevan el espíritu masarrí a las órdenes sufíes de la Persia y de la India». Y termina reconociendo la superioridad de la cultura hispana, que ya fue puesta de manifiesto en el siglo XI por Abenházam de Córdoba.

Es a este otro cordobés al que Asín Palacios consagra su siguiente obra filosófica, la traducción de un texto de Ibn Hazm. Se trata del trabajo que lleva por título Los caracteres y la conducta. Tratado de moral práctica por Abenházam de Córdoba ${ }^{15}$ una especie de diario de notas o confesiones autobiográficas. Ya antes, en 1907, Asín había publicado un primer estudio dedicado al polígrafo cordobés, «La indiferencia religiosa en la España musulmana según Abenházam, historiador de las religiones y las sectas», ${ }^{16}$ donde esbozaba las primeras líneas de lo que luego sería su discurso de ingreso en la Real Academia de la Historia, El cordobés Abenházam, primer historiador de las ideas religiosas. ${ }^{17}$

Más tarde desarrollaría estos conceptos en su gran obra Abenházam de Córdoba y' su historia crítica de las ideas, publicada entre 1927 y 1932 en cinco tomos. El primero de ellos es una exposición de la vida, obra y pensamiento del cordobés, sin igual por ahora, mientras que los cuatro restantes componen la versión castellana del Fisal de Ibn Hazm, es decir, su Historia de las ideas.

De Ibn Hazm nos dice Asín Palacios que fue uno de los más fecundos polígrafos y originales pensadores de la España musulmana: historiador, poeta, literato, jurisconsulto, teólogo, exégeta, moralista, lógico, escritor de política, psicólogo, polemista y metafísico. Consagró su «pasmosa» actividad a todas las ramas de la enciclopedia griega y musulmana, exceptuando las matemáticas, en que se confiesa profano. A todas ellas aplicó el mismo criterio sistemático: la negación de toda autoridad humana, sustituyéndola por el sentido literal de los textos revelados, en materia religiosa, y por la pura razón apodíctica, exenta de prejuicios de escuela, en cuestiones profanas. El nombre de tan genial pensador -dice Asín-falta por completo en las historias generales de la filosofía y, hasta hace poco, apenas sí se le consagraban algunas breves líneas en trabajos de especialistas, que muy vagamente sugerían la trascendencia de su sistema para la teología y el derecho del Islam. Esta ausencia fue llenada con creces por la obra de Asín.

15 Traducción española por M. Asín Palacios, Madrid, Imprenta Ibérica, 1916.

16. Cultura Española, 5 (1907), pp. 297-310.

17 Discurso leido ante la Real Academia de la Historia en la recepción pública del señor don Miguel Asín Palacios el día 18 de majo de 1924, con el discurso de contestación de don Julián Ribera Tarragó, Madrid, Imprenta Maestre, 1924. 
El tomo primero es, todavía hoy, una de las más acabadas monografías que se hayan escrito. Como dice Valdivia, ${ }^{18}$ al lado de la figura central del eximio cordobés se ve palpitante la vida real de la España musulmana del siglo XI. Junto a los hondos problemas psicológicos del biografiado, tanto en el aspecto amoroso como en el religioso, resalta la pasión política, en aquellos días en que se desmoronaba un imperio y se ve con claridad meridiana algo tan interesante como el problema constitucional del Islam español. El análisis de la producción bibliográfica de Ibn Hazm es completo y ponderado; el lector ve cómo la pluma del cordobés compone escritos filosóficos, jurídicos, teológicos, históricos o puramente literarios, entre los que sobresalen dos textos de primer orden, cada uno de ellos suficiente para inmortalizar a cualquiera: el Tawq al-hamâma («Collar de la paloma»), traducido por D. Emilio García Gómez y prologado por D. José Ortega y Gasset; y el Fisal ( «Historia crítica de las ideas religiosas»), que Asín traduce con fascinante prosa.

Todavía Abenházam sería objeto de dos trabajos de Asín Palacios. Uno de ellos, publicado en 1934 y titulado «Un códice inexplorado del cordobés Ibn Hazm», ${ }^{19}$ es importante porque da cuenta en él de un conjunto de epístolas o risâlas de Ibn Hazm, halladas en la Mezquita Fâtih de Estambul, desconocidas en su mayoría, faltando incluso en los registros orientales y occidentales; entre ellas cabe destacar la Risâla marâtib al'ulûm («Epístola sobre la clasificación de las ciencias»), en donde su autor se enfrenta a las ciencias no desde el punto de vista del filósofo, sino del teólogo, aunque no puede decirse que el tratado carezca de valor filosófico y lógico, porque abundan en él datos de interés sobre todas y cada una de las ramas de la enciclopedia griega e islámica, si bien orientado siempre su razonamiento hacia el punto de vista religioso.

El otro artículo es el titulado «El origen del lenguaje y problemas conexos, en Algazel, Ibn Sîda e Ibn Hazm», ${ }^{20}$ en el que Asín estudia el problema del origen del lenguaje en los tres autores. Abenházam se había ocupado de este problema en su Kitâb al-ihkâm fî usûl alahkâm («Libro del sólido conocimiento de los fundamentos jurídicos»), editado en ocho volúmenes en El Cairo. De él traduce Asín Palacios el capítulo 4. ${ }^{\circ}$ del volumen I, que versa Acerca del modo como apareció el lenguaje: si fue por enseñanza divina o por convención humana, donde Ibn Hazm se inclina por la primera opción, al afirmar taxativamente que el origen del lenguaje fue por enseñanza de Allâh, como lo demuestran la revelación y la razón.

Finalmente, un autor andalusí al que, una vez más, Asín Palacios sacó del olvido y fue el primero en señalar su relevancia e importancia como filósofo, fue Ibn al-Sîd de Badajoz (m. 1127), que había pasado a las historias de la cultura arábiga como filólogo y gramático, porque sus biógrafos estaban más preocupados en poner de relieve estas dotes que no las de pensador y filósofo, menospreciadas a los ojos de los cronistas ortodoxos de al-Andalus. Sus escritos filosóficos representan el momento de gestación de los sistemas formulados por los tres grandes pensadores del siglo XII: Avempace, Ibn Tufayl y Averroes.

18 José Valdivia, op. cit., p. 33.

19 Al-Andalus, 2 (1934), pp. 1-56.

20 Al-Andalus, 4 (1936-39), pp. 253-281. 
Asín Palacios habló por vez primera de este autor en un artículo titulado «La tesis de la necesidad de la revelación en el Islam y en la Escolástica», ${ }^{21}$ donde da cuenta de la existencia de un manuscrito en la Biblioteca de El Escorial, que contiene el Kitâb al-masâ'il («Libro de las cuestiones») de Ibn al-Sîd de Badajoz. Son cuestiones de tipo filológico, pero algunas atañen a la filosofía. Y entre ellas llama la atención de Asín Palacios una en que el de Badajoz refiere la discusión mantenida con un amigo suyo sobre la religiosidad o incredulidad del poeta toledano Abû 1-Walîd al-Waqqašî̀, con motivo de dos versos suyos que trataban de filosofía y teología en términos tan oscuros, que se prestaban a interpretaciones diferentes. A propósito de estos versos, Ibn al-Sîd plantea y resuelve a su modo el problema de la armonía entre la fe y la razón. Asín Palacios narra en este artículo las vicisitudes de la tesis de la necesidad de la revelación, desde sus orígenes en la filosofía griega, su aparición en la doctrina cristiana, en al-Fârâbî y Avicena, en Algazel y en Abenházam de Córdoba, en Averroes, en Maimónides y en santo Tomás. Finalmente, ofrece en apéndice la edición árabe y traducción castellana de la cuestión de Ibn al-Sîd de Badajoz.

Más tarde consagró a este mismo autor hispano-musulmán el artículo «Ibn al-Sîd de Badajoz y su Libro de los cercos (Kitâb al-Hadâ'iq)», ${ }^{22}$ en el que estudia la vida de Ibn alSîd y analiza sus principales obras. Edita y traduce su Libro de los cercos, especie de manual para iniciación de los profanos en las doctrinas de los filósofos, que refleja con fidelidad el estado de los conocimientos filosóficos en la España musulmana de fines del siglo XI y comienzos del XII. En este libro aparece el primer intento en al-Andalus de armonizar el pensamiento griego con la teología islámica. Es una obra centrada en la doctrina neoplatónica de la emanación, matizada con reminiscencias neopitagóricas, pero disfrazada en todo momento con las fórmulas tradicionales de la ortodoxia islámica. Su título se debe a que tres círculos o cercos (hadâ'iq) simbolizan las tres etapas de la emanación: las inteligencias celestes, las almas y los seres materiales.

Como hemos ido viendo, Asín Palacios consagró a la filosofía musulmana múltiples trabajos, desde su inicial tesis doctoral sobre Algazel. Repasándolos, asistimos a un descubrimiento por parte de Asín Palacios de autores totalmente desconocidos en la tradición filosófica andalusí, pero sin los cuales difícilmente se podría explicar en su conjunto ese quehacer filosófico, su desarrollo y evolución. Desde los orígenes de este pensamiento, con Ibn Masarra de Córdoba, hasta su época final, con Ibn Tumlûs de Alcira, todos los filósofos andalusíes de los cuales se nos han conservado escritos han sido estudiados por Asín Palacios. Incluso a algunos de ellos nos los ha dado a conocer como tales filósofos.

Como ha señalado D. Miguel Cruz Hernández, el ámbito de la filosofía islámica estudiado por Asín ha sido uno de los más amplios abarcados hasta entonces, tanto por su extensión como por su contenido. La riqueza de éste es tan extraordinaria, que aún hoy 
vivimos de mucho de lo que hizo Asín Palacios. Sus investigaciones en este dominio tuvieron como objetivo, por una parte, rescatar las doctrinas de los filósofos andalusíes y mostrar su origen y continuidad con las del Islam oriental, y, por otra, probar cómo estas doctrinas influyeron en los pensadores cristianos del siglo XIII hasta el punto de abrir nuevas vías de conocimiento en el mundo latino medieval. Por lo excepcional de su obra, por su solidez y rigurosidad científica y por su honradez intelectual, D. Miguel Asín Palacios, ilustre zaragozano, merecía con creces el homenaje que su ciudad natal le ha tributado.

\author{
Rafael Ramón Guerrero \\ Universidad Complutense \\ Depto. de Filosofía III \\ Facultad de Filosofía A \\ E-28040 Madrid
}

